\title{
CARILLAS DE COMPOSITE INYECTADO EN EL PACIENTE PERIODONTAL CON COMPROMISO ESTÉTICO
}

Máster de Prótesis Bucofacial y oclusión. Universidad Complutense de Madridil. Echeverria M, Sorrentino V, Pontevedra P, Muñoz J, Suarez MJ

\section{Introducción \& Objetivos}

Los sistemas adhesivos actuales nos han permitido mejorar los procedimientos clínicos tanto en la evolución de los componentes y su mecanismo de acción, como en la disminución del tiempo operatorio de aplicación de cada uno de ellos, permitiendo un resultado clínico excelente.

El objetivo del presente trabajo fue la rehabilitación del sector anterior mediante composite inyectado en un paciente periodontal

\section{Metodología}

Paciente, de 62 años que acude al Máster en Prótesis Bucofacial de la UCM en demanda estética en el sector anterior.

Tras la exploración, se realizó un encerado diagnóstico sobre los modelos de estudio del paciente. Se planificó la confección de carillas de composite inyectado como solución intermedia previa a la rehabilitación definitiva del paciente.
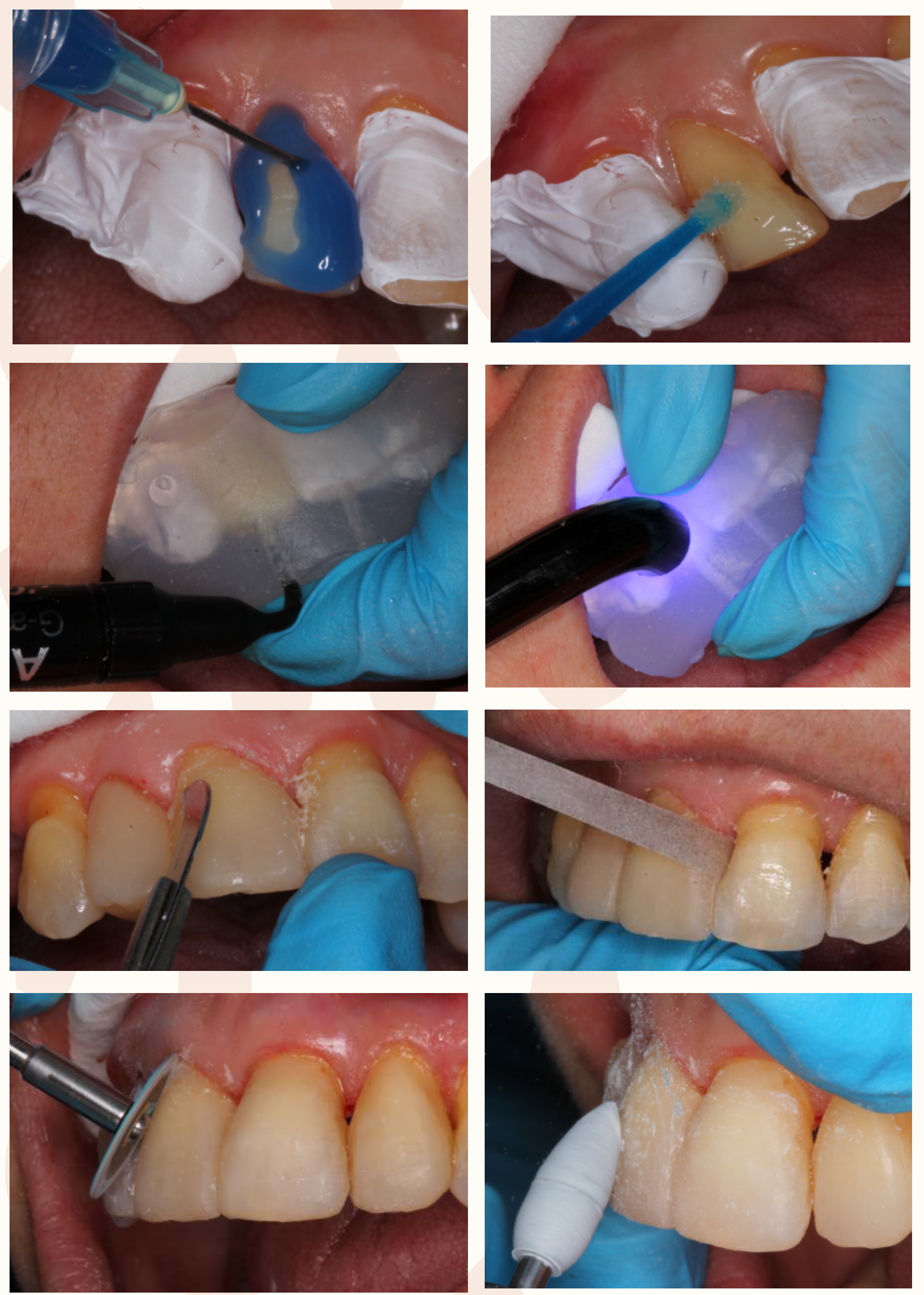

\section{Resultados}

El encerado diagnóstico es imprescindible para unos resultados predecibles de las restauraciones

El resultado final muestra la plena integración de las técnicas adhesivas para el tratamiento de un paciente con técnicas mínimas invasivas.
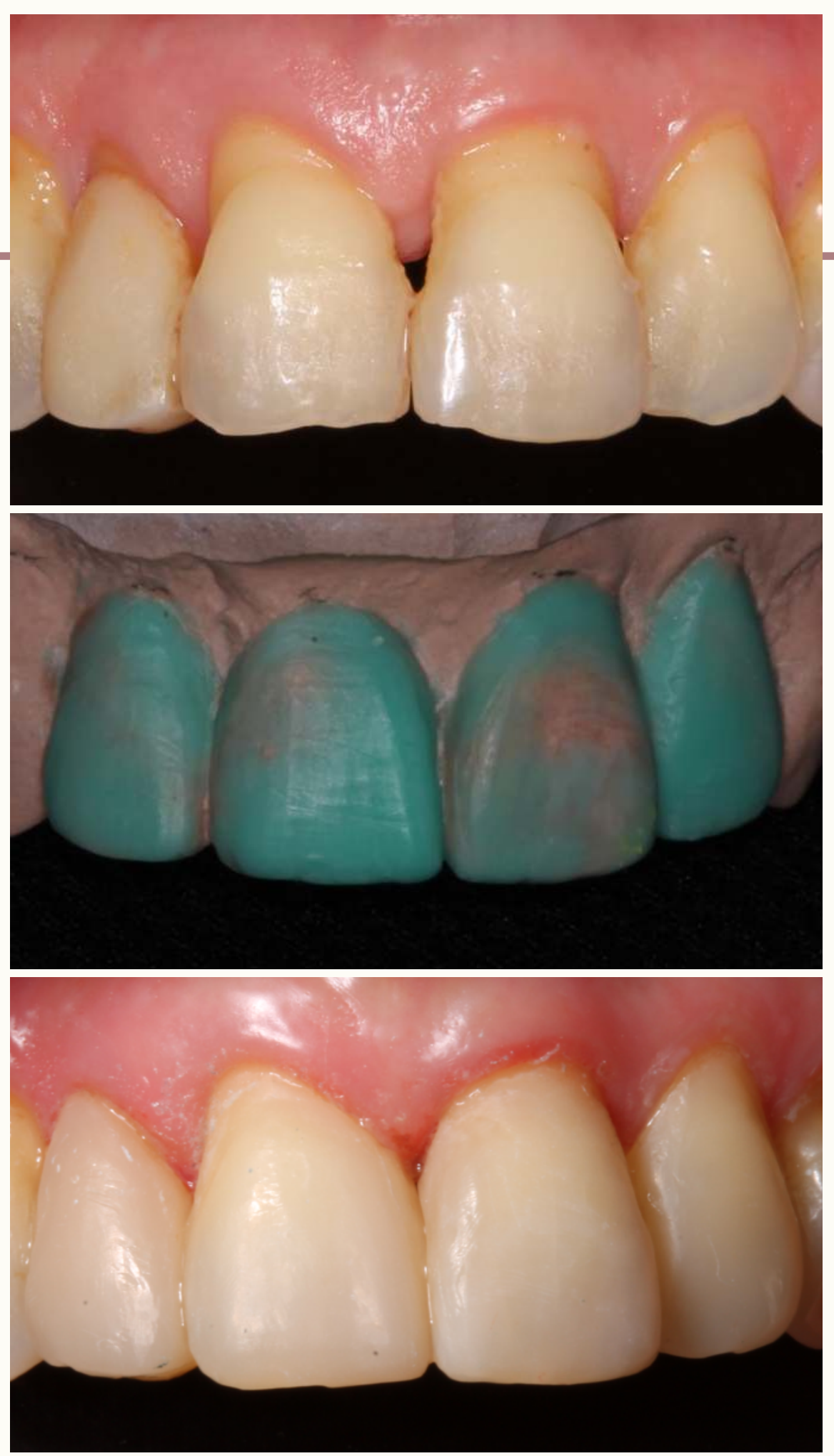

\section{Conclusiones}

Los composites estéticos inyectados suponen un tratamiento innovador para lograr unas restauraciones armónicas, integradas en la sonrisa del paciente.

\section{Referencias}

1. Spreafico RC. Composite Resin Rehabilitation of Eroded Dentition in a Bulimic Patient: a Case Report. Eur J Esthet Dent 2010;3:204-224.

2. Vailati F, Belser UC. Full mouth adhesive rehabilitation of a severely rehabilitation of a severely eroded dentition: the three step technique. Part I. Eur J Esthet Dent 2008;3:30-44.

3. Vailati F, Belser UC. Classification and Treatment of the Anterior Maxillary Dentition Affected by Dentol Erosion:The ACE Classification. Int J Periodontics Restorative Dent 2010;30:559-572.

4. Vailati F, Gruetter L, Belser UC. Adhesively restores anterior maxillary dentitions affected by severe erosion: up to 6-year results of a prospective clinical study. Eur J Esthet Dent 2013;8:506-536 